\title{
Comparison between two perineal procedures for treatment of rectal prolaps
}

\author{
Ahmed Mohamed Abozid, Nabila Mohamed A. Shams, , Yahia Hassan \\ Zayed, Sayid Mostafa .....
}

\author{
Surgical department, faculty of medicine for girls, Al Azhar university
}

\begin{abstract}
s
The optimal surgical procedures for the management of rectal prolapse is still under debate so comparison between two operations were done in our series. Eighteen patients with complete rectal prolaps were treated surgically through the perineum they were divided into two groups. First group were treated by recto-segmoidectomy and levatroplasty to fortify the pelvic floor, the second group were treated by rectopexy using prolene mesh and levetroplasty to fortify the pelvic floor, the mesh was inserted between the rectum and sacrum and fixed through perineal incision. The recurrence rate in group II was less than group I ( $11 \%$ and $33,3 \%$ respectively), while the improvement of incontinence was $(83.3 \%$ and $71.4 \%$ respectively) in both groups. There was no significant difference in hospital stay among both groups. Also there were no other cases of postoperative complications such as anastomotic leak or stricture, affection of the bladder dysfunction in both groups.
\end{abstract}

Aim of work

The aim of this work was to compare the short-term outcome of two different perineal operative procedures in patients with full thickness rectal prolaps.

\section{Introduction}

Complete full thickness rectal prolapse is a distressing condition for the patient. The main objective purposes of treatment are, first to carry out a procedure that safely correct prolapse with minimal morbidity and no mort ality, and secondly to improve the associated incontinence and underling defecatory disorders. Continence resto ration is dependent upon restoring a positive gradient between sphincter and rectal pressure. Many patients are constipated and this play a significant role in the recurrence of prolapse (Bartolo,1996)

It became evident that the receptors of fullness sensation in the rectum are in the pelvic floor muscle rather than in the rectal wall itself (Goligher,1980).
So fortifying the pelvic floor by narrowing it around the rectum is a mandatory step in the operation. This pelvic floor consists of the two levator ani muscles including its different parts (i.e. puborectalis, pubococcygeus and iliococcygeus) ,both coccygeus muscles and the external sphincter ani.

Important factors in the produ ction of prolapse: - 1) Patients with abnormally deep rectovaginal and rectovesical pouch of peritoneum. Those patients are at particular risk. However it is not clear whether a deep pouch associated with rectal prolapse is congenital or is due to childbirth (Kaven et al., 2000). 2) Idiopathic intussusc eption of the upper rectum. Circular invagination of the proximal rectal wall 


\section{Comparison between two perineal procedures}

may occur during defecation and may remain within the rectum (intra rectal intussusception), it may reach the anal canal occluding it (intra anal intussus ception) or extend beyond the anal opening (rectal prolapse). In all cases the intussusceptum occupies the lumen may cause a sense of incomplete empting, which lead to further straining and progress of the condition (Stoker et al., 2000). 3) Most of complete prolapse will show remarkable weak and atonic anal sphincter and levator ani, it is matter of dispute whither this state of affairs is the case or an effect of the prolaps (Goligher, 1980). 4) Anatomical defects include redundant sigmoid colon, loss of fixity of rectum to sacrum, deep cul-de-sac, diastases of the levator ani and patulous anal sphincter all are noticed as a cause of rectal prolapse (Madoff et al, 1992).

The surgical treatment of rectal prolapse is a matter of debate and there is still no consensus on the operation of choice. Recurrence rate have been the standard for judging prolapse operation, but recently emphasis has been placed on functional results (Agachan et al, 1997)

Although abdominal repair has been thought to be associated with better results than perineal repairs; but lower operative risk and quicker recovery, minimal to no postoperative pain and well tolerated to diet without waiting for ileus resolution may favor perineal repair, particularly in elderly poor risk condition. Virtually any type of anaesthesia can be used for perineal procedures, including local if necessary (Agachan et al, 1997 and Williams, 1992)

\section{Material and methods}

Eighteen patients with complete (full thickness) rectal prolapse treated between 1996 and early 2001 by two types of perineal procedures. They were divided into two groups, group I (9 patients) were treated by rectosegm oidectomy and levatroplasty to fortify the pelvic floor, and group II (9 patients) were treated by perineal insertion of polypropylene (prolene) mesh between rectum and sacrum and levatroplasty to fortify the pelvic floor. Pre and postoperative full history, physical examination including PR examination and investigations, speci ally barium study to all patients with lateral view to the pelvis to asses and measure the retro rectal space which is increased in such cases than normal cases were done.

Preoperative preparation of the colon was done as usual.

\section{Surgical procedures}

1.Rectosegmoidectomy was done with the patient in the exaggerated lithotomy position and under general or regional anaesthesia and muscle relaxant. The rectum is prolapsed and the outer cylinder of bowel is divided approximately $2 \mathrm{~cm}$ to $2.5 \mathrm{~cm}$ proximal to the dentate line. The inner cylinder of rectum and sigmoid are placed on traction, the mesenteric vessels are sequentially ligated and divided. When the proximal bowel can not pulled down any further, it is ready for division. At this point in the operation, levatroplasty can be done posterior to the rectum. The specimen is then amputated, taking care to prevent retraction of the proximal colon into the abdomen. The anastom -osis is completed with suture of $0 / 2$ vicril. The anastomosis is reduced into pelvis and finger is passed to make sure that the anastomotic line is sound. In some cases levatroplasty may done through posterior perineal incision, suturing of puborectalis behind rectum, then insertion of 
suction drain and closure of perineal wound.

2.Perineal insertion of prolene mesh between sacrum and posterior rectal wall, through post-anal transverse incision $10-15 \mathrm{~cm}$ in length done under general or regional anaesthesia. While patient in Jack-knife position, dissection of the rectum up to sacral promontory. Three sutures were inserted in the presacral fascia as high as possible by $0 / 2$ prolene fig (1). The prolene mesh was inserted by passing the three sutures at the middle of the mesh and sliding it up to sacral promontory and ligated fig (2) and (3). The rectum is fixed to mesh by $0 / 2$ or $0 / 3$ prolene sutures in the seromuscular layer fig(4). Levatrop lasty done fig (5), then closure with drain.

\section{Results}

A total of 18 patients with complete rectal prolapse were treated by two different surgical operations through the perineum. Thirteen patients were women and 9cases were men. The median age was 58 years (range 32 to 80 years). They were divided into 2 groups. The first group included 9 patients were treated by rectosegmoidectomy and levatroplasty behind the rectum to fortify the pelvic floor. The second group ( 9 patients), were treated by perineal insertion of prolene mesh behind the rectum and levatroplasty. The two operations were compared regarding the following: -

1. Hospital stays.

2. Anastomotic leaks

3. Colorectal anastomotic stricture

4. Recurrence rate

5. Incidence of incontinence

6. Bladder dysfunction

Table 1shows some post operative data which prove no significant differ ence between both groups in the time of hospital stay, anastomotic leaks, colorectal anastomotic stricture or dehiscence, and bladder dysfunction.

Table 2 shows the incidence of preoperative incontinence, which was $77.8 \%$ (7/9 patients) in group 1 and $66.7 \%$ (6/9 patients) in group II. It also shows the postoperative improvement, which was $71.4 \%$ and $83.3 \%$ in both groups respectively.

Table 3 shows the recurrence rate of rectal prolapse after both operations. In group I three cases of recurrence $(33.3 \%)$ and in group II only one case $(11 \%)$, the time of recurrence and management are shown also in the table.

Table 1:- shows the hospital stay and some P.O. complications.

\begin{tabular}{|c|c|c|}
\hline & Group I & Group II \\
\hline Preoperative hosp. stay & $\begin{array}{c}7-10 \text { days } \\
\text { median(8 days })\end{array}$ & $\begin{array}{c}5-8 \text { days } \\
\text { median (7 days) }\end{array}$ \\
\hline Postoperative hosp. stay & $\begin{array}{c}7-12 \text { days } \\
\text { median(10 days })\end{array}$ & $\begin{array}{c}6-10 \text { days } \\
\text { median( } 8 \text { days })\end{array}$ \\
\hline $\begin{array}{c}\text { Anastomotic leaks } \\
\text { colorectal anasto-motic } \\
\text { stricture }\end{array}$ & No cases & ---- \\
\hline $\begin{array}{c}\text { Bladder dysfunction } \\
\text { No cases }\end{array}$ & No cases \\
\hline
\end{tabular}




\section{Comparison between two perineal procedures}

Table 2:- shows the incidence of incontinence

\begin{tabular}{|l|c|c|c|c|}
\hline \multirow{2}{*}{} & \multicolumn{2}{|c|}{ Group I } & \multicolumn{2}{c|}{ Group II } \\
\cline { 2 - 5 } & $\begin{array}{c}\text { No of } \\
\text { patients }\end{array}$ & Percent & $\begin{array}{c}\text { No of } \\
\text { patients }\end{array}$ & Percent \\
\hline $\begin{array}{l}\text { Incidence of } \\
\text { incontinence: } \\
\text {-preoperative } \\
\text {-postoperative }\end{array}$ & $\begin{array}{l}7 \text { cases } \\
2 \text { cases }\end{array}$ & $77.8 \%$ & $\begin{array}{c}6 \text { cases } \\
\text { one case }\end{array}$ & $66.7 \%$ \\
\hline No. Of cases improved & $\begin{array}{c}5 \text { out of } \\
7 \text { cases }\end{array}$ & $71.4 \%$ & $\begin{array}{c}5 \text { out of } 6 \\
\text { cases }\end{array}$ & $83.3 \%$ \\
\hline
\end{tabular}

Table 3: -shows the postoperative recurrence.

\begin{tabular}{|c|c|c|c|c|}
\hline & \multicolumn{2}{|c|}{ Group I } & \multicolumn{2}{|c|}{ Group II } \\
\hline & $\begin{array}{l}\text { No. of } \\
\text { pt. }\end{array}$ & Percent & No. of pt. & Percent \\
\hline $\begin{array}{l}\text { Recurrence of } \\
\text { rectal prolaps }\end{array}$ & 3 cases & $33.3 \%$ & One case & $11 \%$ \\
\hline $\begin{array}{l}\text { Time of } \\
\text { recurrence }\end{array}$ & \multicolumn{2}{|c|}{$\begin{array}{l}\text { Within the first } 18 \\
\text { months }\end{array}$} & \multicolumn{2}{|c|}{ After 6 months } \\
\hline Management & \multicolumn{2}{|c|}{$\begin{array}{l}2 \text { cases, } \\
\text { rectosegmoide- } \\
\text { ctomy\& one refused } \\
\text { reoperation. }\end{array}$} & \multicolumn{2}{|c|}{ Pt. Refused reoperation } \\
\hline
\end{tabular}
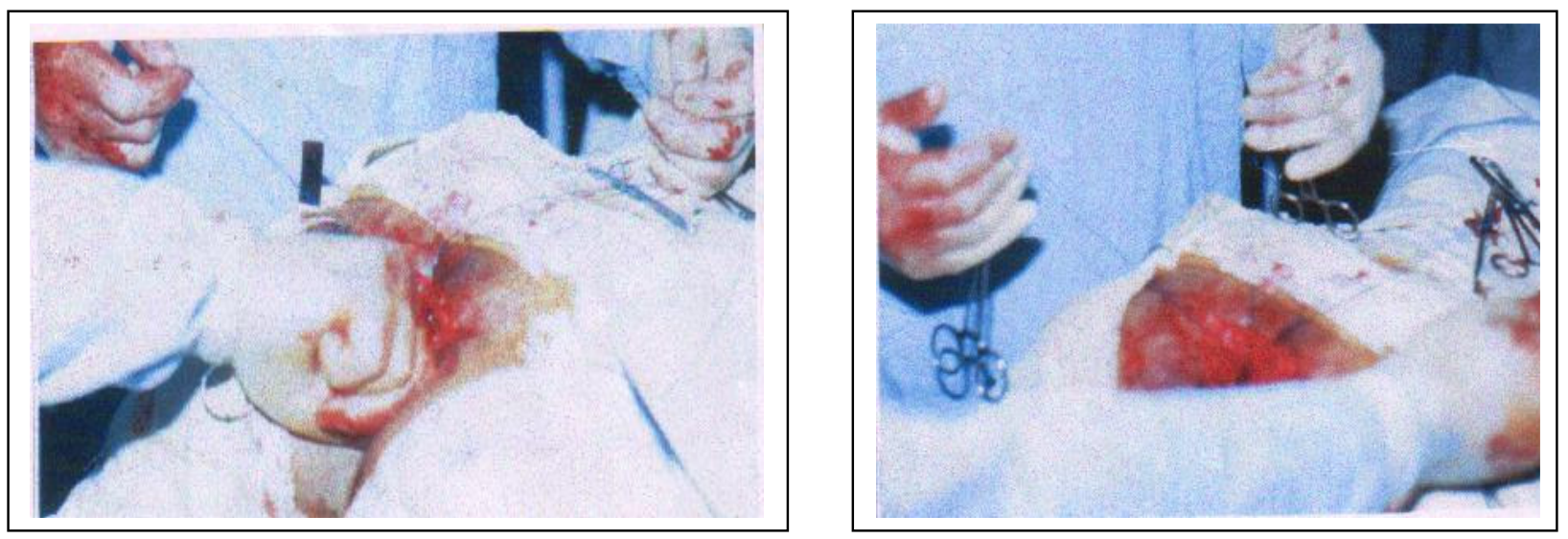

Fig - 1 :-3 Sutures are inserted in pre-sacral fascia at different levels in concavity of sacrum as high as we can 


\section{Ahmed Mohamed Abozid et al,}

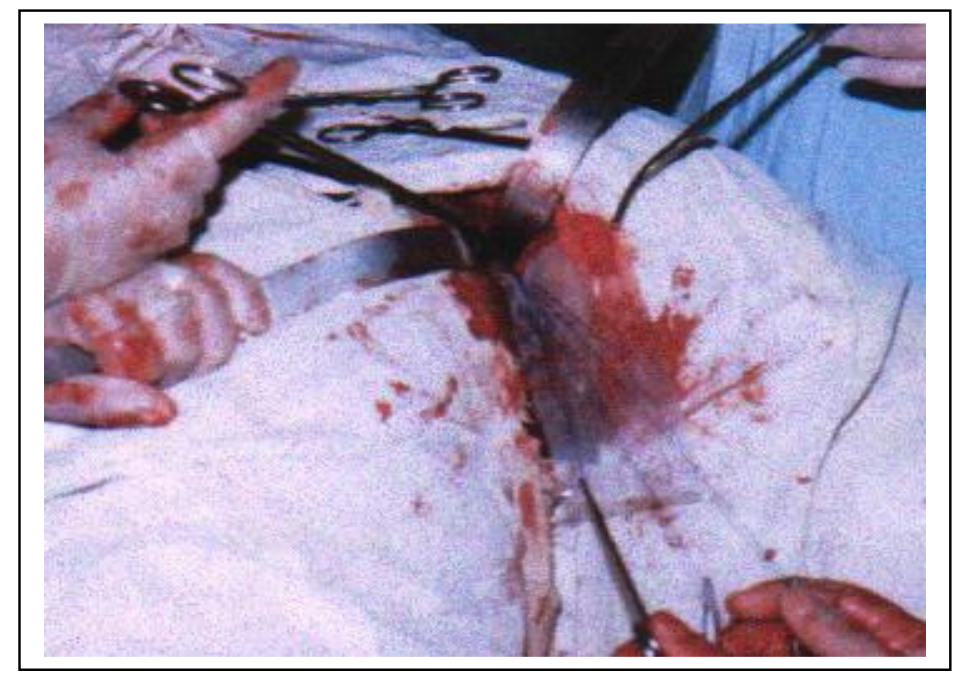

Fig-2 :- The 3 sutures ware passed through the middle of mesh.

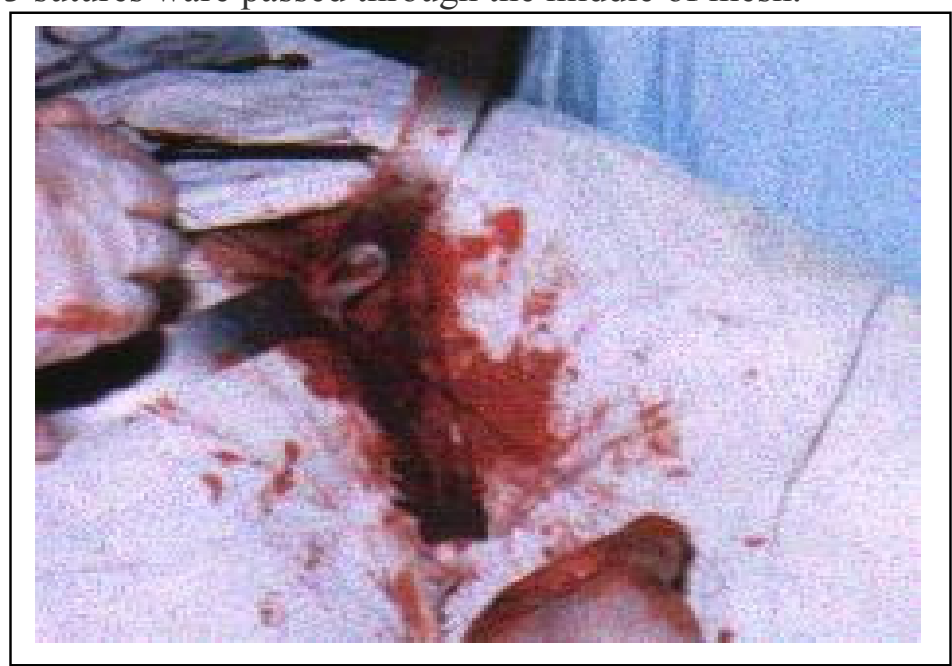

Fig-3 :- The mesh is fixed to per-sacral fascia by 3 - sutures after sliding it high up to level of promontory of sacrum.

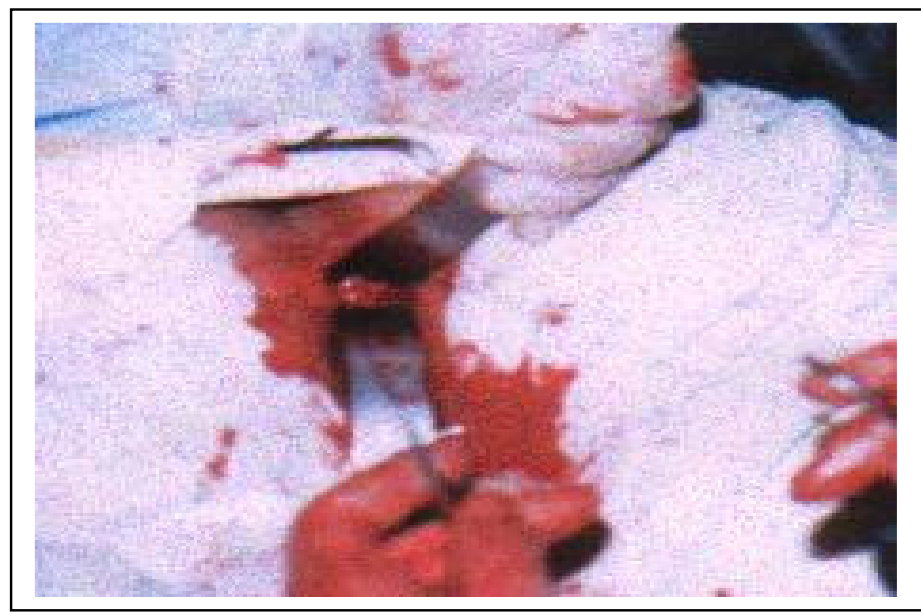

Fig-4 :- Sero-muscular suture between rectum and mesh by No. $0 / 2$ or $0 / 3$ prolene. 


\section{Comparison between two perineal procedures}

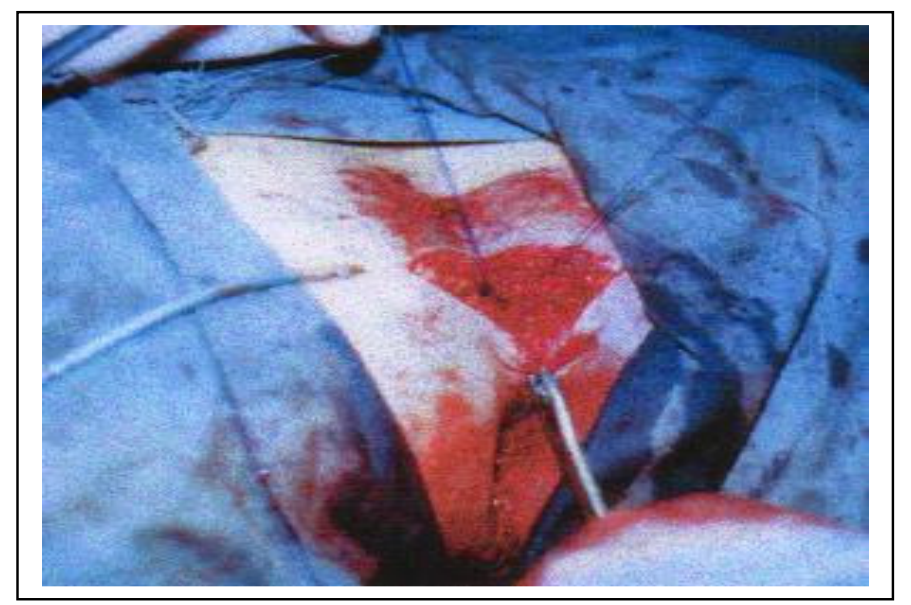

Fig-5 :- Levatoroplasty done by No. 0/2 prolene.

\section{Discussion}

Rectal prolapse is a distressing and difficult problem for both patient and clinician. Difficulties with patient communication and effects of coexi sting medical conditions complicate outcome assessment. The Varity of surgical operations used in the past testifies to the inability of any one technique to provide an adequate solution (Watts and Thomson, 2000). There are numerous techniques for management of rectal prolapse. The procedures can be broken down into basic types which include rectopexy, low anterior resection, perineal proctectomy or anal encirclement procedure (Mangot et al, 1997).

Rectal prolapse was one of the diseases in which surgical techniques were developed to correct an anatomical defects which are redundant sigmoid colon, loss of fixity to sacrum, deep culde-sac, diastases of levator ani muscles and patulous anal sphincter (Graham Williams, 1995). Golligher in 1989 showed that the incidence of recurrence rate after rectosegmoidectomy alone is $60 \%$, and only $10 \%$ if it is associated with levatroplasty to fortify the pelvic floor. The high incidence of recurrence rate after rectosegmoidectomy is due to widening of the retro rectal space proved by barium study after operation. This much widening put the rectum and anal canal in one line and diastases of pelvic floor allowing rectum to prolapse again. In our theses plication of pelvic floor hiatus and increase of the angulation between rectum and anal canal, decreased the recurrence, and improved the incontinence. Moreover, increase of corrugations around anus and tone of sphincter is improved noticed by P.R examination.

In our series, perineal rectosegm -oidectomy with levatroplasty yielded a recurrence rate of $20 \%$ (3/15 patients). This rate is higher than rates reported by Keighley et al (1983), Andersen et al (1984), Holmstrom et al (1986), Roberts et al (1988), Agachan et al (1997), and kim et al (1999), which are from $0 \%$ to $10 \%$, while the recurrence rate in our cases of perineal mesh insertion was $6.67 \%(1 / 15$ patients $)$ which is coinc ides with these results. Recurrence of prolapse in group I may be due to inad equate mobilization and resection of the 
redundant rectum and sigmoid colon. While in group II it may be due to improper fixation of the rectum to the mesh.

Among patients with rectal prolapse, anal control is defective in 40\%-80\% (Jorge and Wexner, 1993); this rate is similar to that noted in our study $(77.8 \%$ and $66.7 \%$ in group I and II). The mechanism involved is still unclear and is probably multifactorial. Chronic stretching of the anal sphincter, inhibition of the internal sphincter with the recto anal inhibitory reflex, impairment of anorectal sensation, and denervation of the pelvic floor muscles are all factors that have been considered as attributing to loss of anal control in these patients (Agachan et al, 1997).

Prasad et al, in 1986, reported that 22 of 25 incontinent patients had significantly improved continence within 4 weeks of surgery. Ramanujan and Vencatesh, 1988 reported a 78\% success rate. Agachan, 1997 observed $66 \%$ success rate with combined perineal rectosegmoidectomy and leva troplasty. In our series we recorded $71.4 \%$ success rate with the same procedure, and $81.3 \%$ with perineal ins ertion of prolene mesh behind rectum.

Summary:- there is no ideal surgical procedure, that is appropriate for all patients with rectal prolapse. Elderly poor risk patients are best treated through perineal approach, it is well tolerated by these patients. The higher recurrence rate is offset by the minimal morbidity and faster recovery.

The choice procedure for the young, fit individual is more contro versial. There is growing trend to offer these patients a perineal procedure because of ease and simplicity despite the higher recurrence rate. More over resent studies have documented substantial restoration of continence and improvement in constipation with perineal procedure (Oliver et al, 1994, keighley et al,1983 and Andersen et al,1984). However young fit patients do tolerate an abdominal operation well and can be assured of lower recurrence and functional results particularly with respect to restoration of continence.

In our series, we operated upon 2 groups of patients 15 for each through perineal approach, the first is rectosegmoidectomy and levatroplasty and the second is prolene mesh rectopexy and levatroplasty. We comp ared the results of both operations and we found recurrence rate $33.3 \%$ and $11 \%$ and improvement of incontinence rate $71.4 \%$ and $83.3 \%$ respectively in both groups.

Conclusion:- perineal operations for rectal prolapse are safe for both fit and risk patients. Levatroplasty should be a part of any procedure. The use of mesh rectopexy with levatroplasty is superior to rectosegmoidectomy with levatro plasty as regard recurrence rate and improvement of incontinence.

\section{References}

1. Agachn F, Reissman $\mathbf{P}$, Pfeifer $\mathbf{J}$, et $a l$ : comparison of three perineal procedures for treatment of rectal prolapse. Southern Med J 1997; 90:925-32

2. Andersen JR, Wilsen BG, Parks TG: complete Rec.Prol.The result of Ivalon sponge rectopexy. postgrad. med.j 1984; 70:229-232.

3. Bartolo DC: Rectal prolaps. Br J S 1996; 83:3-5

4. Goligher JC: Surgery of the anus rectum and colon. , $\left(1^{\text {st }}\right)$ edition, Bailliere tindall, London 1980; 10: 224258.

5. Holmstrom B, broden G, dolk A: results of ripstein operation in the treatment of rectal prolapse and internal procipentia. Dis. Colon rectum 1986; 29:845-848 


\section{Comparison between two perineal procedures}

6. Jorge JMN, Wexner SD: etiology and management of fecal incontinence. Des Colon rectum 1993; 36:77-79.

7. Kaven B and Bernhard: the depth of Douglas pouch in parous and nulliparous women without genital prolapse and in patients with genital prolapse. Am J Obst Gyna 2000; 182:450-454.

8. keighly MRB, fielding JA, Alexander $\mathbf{J}$ : Results of marlex mesh rectopexy for rectal prolapse in 100 consecutive patients.Br J surg 1983;70:229-232

9. Kim DS, Tsang CB, Wong WD, Lowry AC, Goldberg SM, and Madoff RD: complete rectal prolapse: evolution of management and results. Dis colon rectum 1999;42:460-466.

10. Madoff RD, Williams JG, Wong WD, Rothenburger DA, Goldberg SM. Long term functional results of colon resection and rectopexy for overt rectal prolapse. Am J Gstroent 1992;87:101104.

11. Oliver GC, Vachon D, Eisenstat TE, et al: Delorme's procedure for complete rectal prolapse in severely debilitated patients: an analysis of 41 cases. Dis colon rectum 1994; 37:461-467.
12. Prasad ML, Pearl RK, Abcarian H, et al: perineal proctectomy, poste -rior rectopexy and postanal levator repair for treatment of rectal prolaps. Dis Colon Rectum 1986; 29:547-552

13. Ramanujam PS, Venkatesh KS: perineal excision of rectal prolapse with posterior levator repair in elderly high risk patients. Dis Colon Rectum 1988; 31:704-706

14 Roberts PL, Schoetz DJ, Coller JA, et al: ripstein procedure. Lahey clinic experience. Arch surger.1988; 123:554557

15 Stoker J, Rociu E, Wiersma TJ, and Lameris JS: Imaging of anorectal disease. Br.J.S 2000; 87:10-27

16 Watts AMI and Thompson MR: evaluation of Delorme's procedure as a treatment for full thickness rectal prolapse.Jornal of surgery 2000;87:218222.

17 Williams JG, Gothenburger DA, Madoff RD, Goldberg SM. Treatment of rectal prolapse in elderly by rectosegmoidectomy. Dis Colon Rectum 1994; 37:456-460. 


\section{مقارنة بين عمليتين لعلاج السقوط الثرجى الكامل عن طريق العجان}

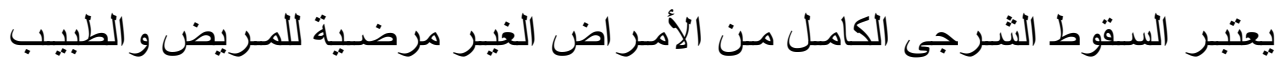

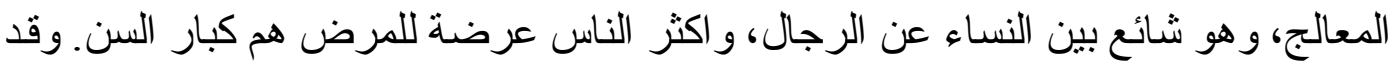

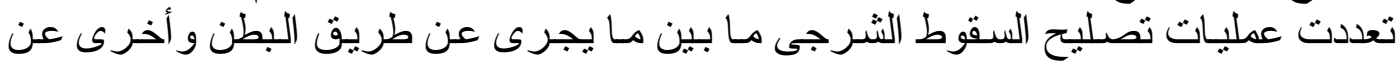
طريق العجان

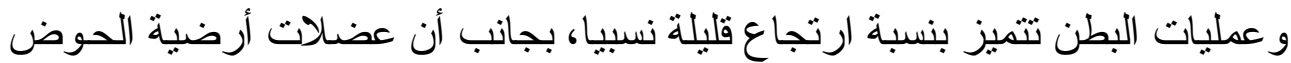

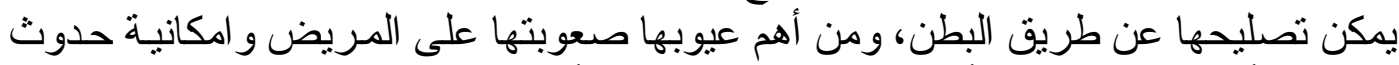

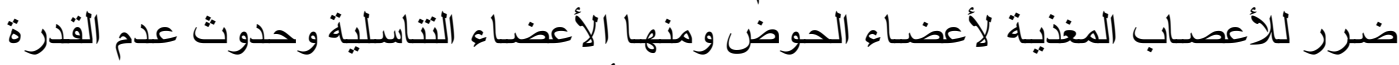

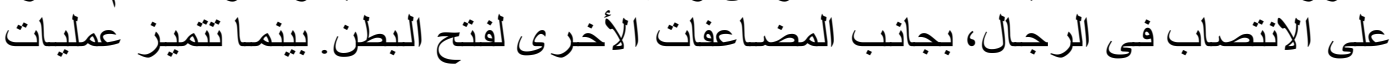

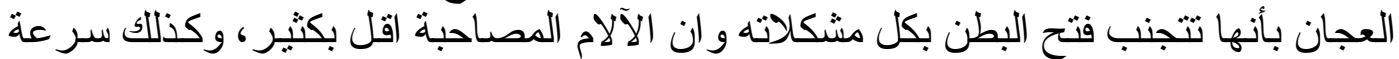

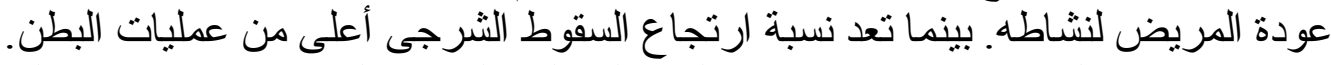

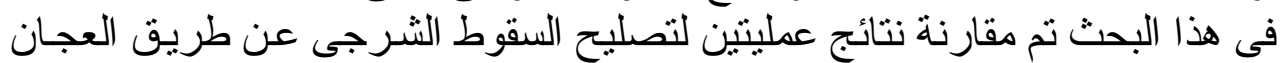

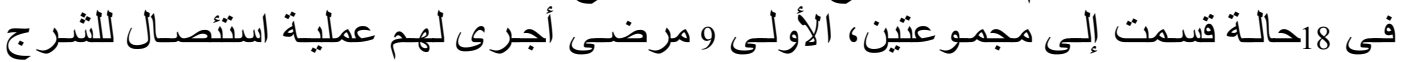

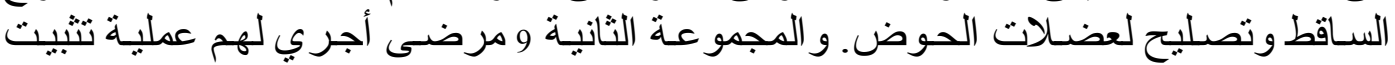

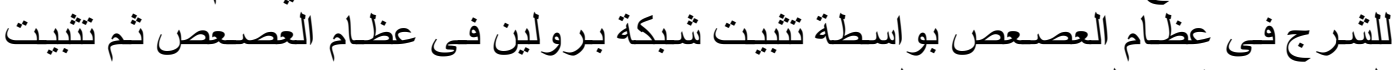

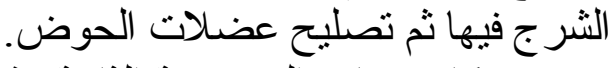

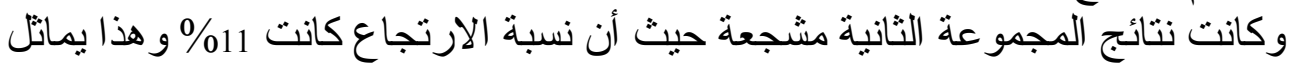

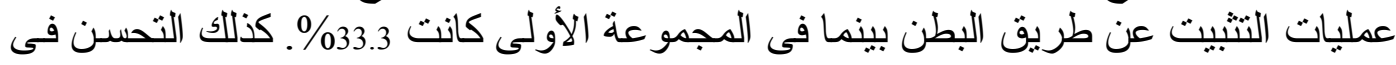

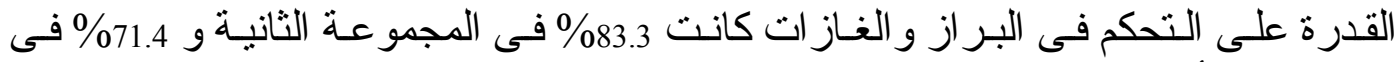
المجموعة الأولى من مجموع المرضى اللذين كانو ا يعانون من هذه المشكلة قبل العملية. 